\title{
Dual Inhibition of Salmonella enterica and Clostridium perfringens by New Probiotic Candidates Isolated from Chicken Intestinal Mucosa
}

\author{
Ayesha Lone ${ }^{1,+}$, Walid Mottawea ${ }^{1,2,+} \mathbb{D}$, Yasmina Ait Chait ${ }^{1}$ and Riadh Hammami ${ }^{1, *(D)}$ \\ 1 NuGUT Research Platform, School of Nutrition Sciences, Faculty of Health Sciences, University of Ottawa, \\ Ottawa, ON K1H8M5, Canada; alone069@uottawa.ca (A.L.); wmott020@uottawa.ca (W.M.); \\ yaitc043@uottawa.ca (Y.A.C.) \\ 2 Department of Microbiology and Immunology, Faculty of Pharmacy, Mansoura University, \\ Mansoura 35516, Egypt \\ * Correspondence: riadh.hammami@uottawa.ca; Tel.: +1-613-562-5800 (ext. 4110) \\ + Those authors Contributed equally to this work.
}

check for updates

Citation: Lone, A.; Mottawea, W.; Ait Chait, Y.; Hammami, R. Dual

Inhibition of Salmonella enterica and Clostridium perfringens by New

Probiotic Candidates Isolated from Chicken Intestinal Mucosa. Microorganisms 2021, 9, 166. https://doi.org/doi:10.3390/ microorganisms 9010166

Received: 15 December 2020 Accepted: 8 January 2021 Published: 13 January 2021

Publisher's Note: MDPI stays neutral with regard to jurisdictional clai$\mathrm{ms}$ in published maps and institutional affiliations.

Copyright: $(\odot 2021$ by the authors. Licensee MDPI, Basel, Switzerland. This article is an open access article distributed under the terms and conditions of the Creative Commons Attribution (CC BY) license (https:// creativecommons.org/licenses/by/ $4.0 /)$.

\begin{abstract}
The poultry industry is the fastest-growing agricultural sector globally. With poultry meat being economical and in high demand, the end product's safety is of importance. Globally, governments are coming together to ban the use of antibiotics as prophylaxis and for growth promotion in poultry. Salmonella and Clostridium perfringens are two leading pathogens that cause foodborne illnesses and are linked explicitly to poultry products. Furthermore, numerous outbreaks occur every year. A substitute for antibiotics is required by the industry to maintain the same productivity level and, hence, profits. We aimed to isolate and identify potential probiotic strains from the ceca mucosa of the chicken intestinal tract with bacteriocinogenic properties. We were able to isolate multiple and diverse strains, including a new uncultured bacterium, with inhibitory activity against Salmonella Typhimurium ATCC 14028, Salmonella Abony NCTC 6017, Salmonella Choleraesuis ATCC 10708, Clostridium perfringens ATCC 13124, and Escherichia coli ATCC 25922. The five most potent strains were further characterized for their probiotic potential (i.e., sensitivity to antibiotics and tolerance to gastrointestinal physicochemical conditions). Our analyzed lactobacilli strains exhibited some interesting probiotic features while being inhibitory against targeted pathogens.
\end{abstract}

Keywords: poultry; Lactobacilli; probiotic candidates; antimicrobial activity; bacteriocins; Salmonella; Clostridium perfringens

\section{Introduction}

Salmonella is one of the leading causes of foodborne diseases worldwide, followed closely by Clostridium perfringens [1,2]. In Europe, one in four human infections by Salmonella shows resistance to three or more antimicrobials that are routinely used in human and animal medicine [3]. In the US, 5\% of tested Salmonella was found to be resistant to five or more types of antibiotics in 2011, and, by the end of 2018, the number of Salmonella outbreaks in the US was sitting at fourteen. Five were linked to chickens, raw chickens, and eggs, which was twice as many as seen in 2015 and 2016 [4,5]. As for C. perfringens, the CDC estimates that it causes 1 million cases of foodborne illnesses per year with a substantial economic loss to the poultry industry due to the high rate of poultry mortality [6,7].

Exposure to chicken and other poultry products has been identified as a common source of both campylobacteriosis and salmonellosis outbreaks and as a risk factor for sporadic infection with these pathogens [8]. With the recent ban on the use of antibiotics as growth promoters and for prophylaxis $[9,10]$, producers will have to change the way the industry raises broilers by trying to mitigate the spread of poultry pathogens while maintaining the productivity of the past. Proposed alternatives to antibiotic use in poultry feeds 
include phytogenic feed additives, feed acidifiers, antimicrobial peptides, bacteriophages, antibodies, prebiotics, and probiotics [11,12]. Probiotics are promising alternative growth promoters, and evidence of their beneficial effects is accumulating in poultry production [13]. The mode of action of probiotic feed additives in poultry is mainly based on four principles: (i) maintaining normal intestinal microbiota by competitive exclusion and antagonism [14], (ii) altering metabolism by increasing digestive enzyme activity, and decreasing bacterial enzyme activity and ammonia production [15], (iii) improving feed consumption and digestion [16], and (iv) stimulating the immune system [17]. Furthermore, they exert indirect antimicrobial effects against pathogenic bacteria, which minimize the possibility of developing antimicrobial resistance among the bird commensals, while enhancing the proliferation of beneficial microbes [12]. Particularly, bacteriocins and their producing probiotics, such as Enterococcus spp. and some E. coli strains, have acquired great attention as natural antibiotic alternatives in the food industry [17-19]. However, the prevalence of antimicrobial resistance genes (ARGs) and virulence factors among the investigated strains hinder their application in the food industry [18]. While many studies exist that show beneficial effects of such probiotics in chickens, in vitro, in vivo, or both, the results have been inconsistent [20]. Broad spectrum probiotics isolated from chicken indigenous microbiota with dual activity against Salmonella enterica and Clostridium perfringens are still unidentified. In this study, we aimed to isolate potential probiotic candidates from the ceca mucosa of broiler chicken that can control the growth of common poultry pathogens including Salmonella enterica and Clostridium perfringens.

\section{Materials and Methods}

\subsection{Bacterial Strains and Culture Conditions}

Indicator strains of Salmonella enterica serovar Abony NCTC 6017, Salmonella enterica serovar Typhimurium ATCC 14028, and Salmonella enterica serovar Choleraesuis ATCC 10708 were cultured in de Man, Rogosa and Sharpe (MRS; Criterion, Hardy Diagnostics, CA, USA) broth and incubated aerobically at $37^{\circ} \mathrm{C}$ for $24 \mathrm{~h}$. Clostridium perfringens ATCC 13124 was cultured in fastidious anaerobic broth (LAB M, Heywood, UK) supplemented with $(0.5 \%)$ yeast extract and incubated anaerobically for $24 \mathrm{~h}$ at $37^{\circ} \mathrm{C}$. Isolated strains from this study were cultured in MRS broth supplemented with $(0.1 \%)$ L-cysteine for $24 \mathrm{~h}$ at $37^{\circ} \mathrm{C}$ under aerobic or anaerobic (a gas mixture of $5 \% \mathrm{CO}_{2}, 5 \% \mathrm{H}_{2}$, and $90 \% \mathrm{~N}_{2}$, Whitley Anaerobe Systems A35, Don Whitley Scientific, Bingley, UK) conditions. All isolated strains were purified three times on respective agar media plates. The strains were maintained in $25 \%$ glycerol stock at $-80{ }^{\circ} \mathrm{C}$ until use.

\subsection{Preparation of Ceca Mucosal Scrapings from the Chicken Intestinal Tract}

Broiler chicken intestinal tracts were obtained from a local commercial slaughterhouse (Berube Poultry, Mountain, Canada) and Ringers solution $\left(\mathrm{NaCl} 7.2 \mathrm{~g} / \mathrm{L}, \mathrm{CaCl}_{2} 0.17 \mathrm{~g} / \mathrm{L}\right.$, and $\mathrm{KCl} 0.37 \mathrm{~g} / \mathrm{L}$ at $\mathrm{pH} 7.3$ ) supplemented with (0.1\%) L-cysteine (VWR, Solon, OH, USA) was poured over them and added to an anaerobic jar to preserve the microorganisms during transportation. All samples were processed upon arrival to the laboratory within an hour of collection. The intestinal tract was laid out, Ringers solution $+(0.1 \%)$ L-cysteine sprayed over the tracts, and the mesentery, liver, heart, pancreas, and gallbladder were removed. Butchers twine was used to knot directly above and under the ceca to prevent the mixing of gut contents. The ceca were cut open, contents were removed, and then the mucosa was scrapped and added to a 15-mL centrifuge tube. Mucosal scrapings from both ceca were added to the same tube. The dissection equipment was cleaned and sterilized with $70 \%$ ethanol before scraping off the mucosa. All intestinal tracts were screened for Salmonella infection using MacConkey Agar. 


\subsection{Determination of Antibacterial Activity}

\subsubsection{Screening Using Double Layer Technique}

The protocol was modified from Reference [21]. Furthermore, $9 \mathrm{~mL}$ of de Man, Rogosa, and Sharpe (MRS) broth (Criterion, Hardy Diagnostics, CA, USA) supplemented with $(0.1 \%)$ L-cysteine was added to the $15-\mathrm{mL}$ centrifuge tube containing ceca mucosal scrapings, vortexed to ensure mixing, and then 10-fold serial dilutions were performed. Aliquots of $100 \mu \mathrm{L}$ were spread onto either $1.2 \%$ MRS agar or tryptic soy agar (TSA) $(1.2 \%)$ (Criterion, Hardy Diagnostics, CA, USA) supplemented with (0.5\%) Yeast extract (YE) (Biobasic, NY, USA), seeded with $1 \%$ S. Abony NCTC 6017. One set of Petri plates was incubated aerobically, and the other set was incubated anaerobically at $37^{\circ} \mathrm{C}$ for $48 \mathrm{~h}$ or $72 \mathrm{~h}$, respectively. Those colonies that yielded inhibition zones were selected and cultured in MRS broth $+(0.1 \%)$ L-cysteine for $24 \mathrm{~h}$ to be used for a spot-on lawn method as a first mean of screening.

\subsubsection{Spot-on Lawn Method}

The protocol was adapted from Reference [22]. An aliquot of $3 \mu \mathrm{L}$ of an overnight culture of isolated strains were spotted onto the surface of MRS $(1.2 \%)$ agar or tryptic soy broth with yeast extract (TSBYE) $(1.2 \%)$ agar pre-seeded with $1 \%$ overnight culture of $S$. Abony NCTC 6017 and incubated either aerobically or anaerobically at $37^{\circ} \mathrm{C}$ for $24 \mathrm{~h}$. Those strains that showed inhibition zones were selected, purified three times by streaking on their respective media, and stock solutions prepared and maintained at $-20{ }^{\circ} \mathrm{C}$ and stored at $-80{ }^{\circ} \mathrm{C}$ in their represented media containing $50 \%$ glycerol $(v / v)$.

\subsubsection{Agar Well-Diffusion Method}

The protocol was adapted from Reference [23]. Briefly, $25 \mathrm{~mL}$ of sterile MRS Agar $(1.2 \%)$ was seeded with $1 \%$ S. Abony NCTC 6017 , poured into a sterile petri dish, and allowed to solidify at room temperature for $30 \mathrm{~min}$. Afterward, the wide end of a $5 \mathrm{~mL}$ pipette was used to create wells in the agar, and $80 \mu \mathrm{L}$ of cell-free supernatant (CFS) or ciprofloxacin (control) was added to the wells. The plates were stored at $4{ }^{\circ} \mathrm{C}$ for $1 \mathrm{~h}$ to allow the CFS to diffuse through the agar and then incubated aerobically at $37^{\circ} \mathrm{C}$ for $24 \mathrm{~h}$. The diameter of the inhibition zone was measured. The plates were prepared in duplicate and repeated with the other indicator strains. The most active isolated strains and S. Typhimurium ATCC 14028 strain were chosen for the critical-dilution assay.

\subsubsection{Critical Dilution Assay}

Antimicrobial activity was determined using the microtitration method adapted from Reference [22]. Briefly, in a 96-well flat-bottomed plate (VWR, Monroeville, PA, USA), $125 \mu \mathrm{L}$ of CFS was added to MRS broth and used to perform two-fold serial dilutions, which were then seeded with $50 \mu \mathrm{L}$ of $10^{6} \mathrm{CFU} / \mathrm{mL}$ of $S$. Typhimurium ATCC 14028 . The plates were incubated for $24 \mathrm{~h}$ and absorbance at $600 \mathrm{~nm}$ was measured every $20 \mathrm{~min}$ using a Tecan Microplate Reader Spark ${ }^{\circledR}$ (Grödig, Austria).

\subsection{Identification of Isolated Strains by $16 S$ rRNA Sequencing}

The active strains were identified by $16 \mathrm{~S}$ rRNA. Genomic DNA was extracted from the overnight culture of isolated strains using a NucleoSpin Microbial DNA kit (MachereyNagel, Duren, Germany) as per manufacturer's instructions. The DNA's concentration and purity was then determined using the Tecan NanoQuant plate (Austria) by comparing the absorbance ratio at $260 \mathrm{~nm}$ to $280 \mathrm{~nm}$.

The $16 \mathrm{~S}$ rRNA gene was amplified by a PCR thermal cycler (Eppendorf, Hamburg, Germany) using the universal primers 1391-R (5'-GACGGGCGGTGTGTR) and Bact-8F (5'-AGAGTTTGATCCTGGCTCAG-3') (Millipore-Sigma, Cleveland, OH, United States), in a total volume of $50 \mu \mathrm{L}$ [24]. The reaction mixture contained $1 \times$ PCR buffer (Invitrogen, Carlsbad, CA, USA), $1.5 \mathrm{mM} \mathrm{MgCl} 2$ (Invitrogen, Carlsbad, CA, USA), $0.2 \mathrm{mM}$ NTPS (Invitrogen, Carlsbad, CA, USA), $1 \mu \mathrm{M}$ of each primer, $0.2 \mu \mathrm{L}$ of a Taq polymerase (Invitrogen), 
$36.3 \mu \mathrm{L}$ of $\mathrm{H}_{2} \mathrm{O}$, and $20 \mathrm{ng}$ of bacterial DNA. The thermal cycler program consisted of an initial hold at $95{ }^{\circ} \mathrm{C}$ for $5 \mathrm{~min}$ for denaturation and polymerase activation, 30 cycles of $94{ }^{\circ} \mathrm{C}$ for $30 \mathrm{~s}, 55{ }^{\circ} \mathrm{C}$ for $30 \mathrm{~s}, 72{ }^{\circ} \mathrm{C}$ for $1 \mathrm{~min} 30 \mathrm{~s}$, and a final elongation step of $5 \mathrm{~min}$ at $72{ }^{\circ} \mathrm{C}$. The PCR products were then purified using a QIAquick PCR purification kit (Qiagen, Hilden, Germany) and sequenced by the Ottawa Hospital Research Institute's DNA sequencing facility (Ottawa, ON, Canada). The resulting sequences were aligned against $16 \mathrm{~S}$ ribosomal RNA database using the BLAST program [25]. The criterion used to identify an isolate to the species level was having an identity greater than $99 \%$ in the $16 \mathrm{~S}$ rRNA gene sequence.

\subsection{Whole Genome Sequencing}

The whole genome sequencing library was prepared using Nextera ${ }^{\mathrm{TM}}$ DNA Flex Library Prep (Illumina; San Diego, CA, USA) as per its protocol. The prepared library was paired end sequenced $(2 \times 151 \mathrm{bp})$ in a 1/20 Miseq run with Illumina MiSeq platform (NuGUT Research Platform, University of Ottawa, Ottawa, ON, Canada) using a 300-bp MiSeq Reagent Kit v2 (Illumina, San Diego, CA, USA). The generated reads were de-novo assembled using the Velvet Assembler V1.0.0 incorporated in Illumina BaseSpace Sequence Hub (Illumina). Kraken2 Metagenomics V2.0.0 [26] was used to assign the taxonomy to the generated reads. The assembled contigs were annotated using Rapid Annotation using Subsystem Technology (RAST) server [27-29]. BAGEL4 and antiSMASH 5.0 [30] was used to screen for secondary metabolite genes in the assembled genomes. The assembled contigs were submitted to the PHAge Search Tool Enhanced Release (PHASTER) [31] for identification and annotation of the prophage sequences.

\subsection{Safety Evaluation and In Vitro Probiotic Potential}

\subsubsection{Antibiotic Susceptibility Test}

The protocol was adapted from Reference [22]. In a 96-well flat-bottomed plate, $100 \mu \mathrm{L}$ of twice the selected antibiotic concentration was added to $100 \mu \mathrm{L}$ of MRS broth with $(0.1 \%)$ L-cysteine and used to perform two-fold serial dilutions. The wells were then seeded with $100 \mu \mathrm{L}$ of $10^{5} \mathrm{CFU} / \mathrm{mL}$ of the selected bioactive strains. The absorbance at $600 \mathrm{~nm}$ was measured using Tecan Microplate Reader Spark ${ }^{\circledR}$ (Grödig, Austria) at $0 \mathrm{~h}$ and then incubated in the anaerobic chamber for $24 \mathrm{~h}$. Then absorbance was read once again. The minimum inhibitory concentration (MIC) was determined as the lowest concentration of the antibiotic that inhibited the visible growth of the microorganism. The antibiotics tested were ampicillin, vancomycin, gentamycin, streptomycin, erythromycin, tetracycline, and chloramphenicol (All antibiotics were obtained from Alfa Aesar, Mississauga, Canada apart from gentamycin, which was from VWR, New York, NY, USA).

\subsubsection{Tolerance to Bile Salts and Gastric Acidity}

The protocol was adapted from Reference [17]. Simulated gastric juice (SGJ) and intestinal juice (SIJ) was prepared according to the United States Pharmacopoeia (USPCCE 2004) [32]. SIJ consisted of $10 \mathrm{~g} \mathrm{~L}^{-1}$ pancreatin (Wards Science, St Catherines, Canada) dissolved in $0.05 \mathrm{~mol} \mathrm{~L}^{-1} \mathrm{KH}_{2} \mathrm{PO}_{4}$, at pH 7.4, and SGJ consisted of $2 \mathrm{~g} \mathrm{~L}^{-1}$ pepsin (Wards Science, St Catherines, Canada) and $2 \mathrm{~g} \mathrm{~L}^{-1} \mathrm{NaCl}$ at $\mathrm{pH} 1.5$ [32]. The SIJ was used to test bile salts' tolerance of the isolated strains, and the SGJ was used to test tolerance to $\mathrm{pH}$. To the SIJ, oxgall bile salts (VWR, Mississauga, Canada) were added at varying concentrations of $0.0 \%, 0.1 \%, 0.2 \%, 0.3 \%, 0.4 \%, 0.6 \%, 0.8 \%, 1 \%$, and $1.5 \%$ to mimic the physiological concentrations of the intestinal tract [17]. The SGJ was divided into centrifuge tubes with a pH of 2.6 and 4.5, the gizzard's $\mathrm{pH}$, and the crop, respectively [33]. The $\mathrm{pH}$ was adjusted using $5 \mathrm{~N} \mathrm{NaOH}$ or $1 \mathrm{M} \mathrm{HCl}$. All fluids were filter sterilized with a $0.45 \mu \mathrm{m}$ filter.

A 96-well flat-bottomed plate was used to determine the tolerance to bile salts. $100 \mu \mathrm{L}$ of intestinal juice with different bile salt concentrations was added to the wells, in triplicate, and followed by $100 \mu \mathrm{L}$ of overnight cultures of the isolated strains. The resulting $200 \mu \mathrm{L}$ was mixed with a multi-channel pipette. Enumerations using the drop plate method were 
performed at $0,3,6$, and $24 \mathrm{~h}$. The plate was incubated anaerobically at $37^{\circ} \mathrm{C}$. Similarly, the tolerance to $\mathrm{pH}$ was tested using $100 \mu \mathrm{L}$ of $\mathrm{pH}$-adjusted gastric juice seeded with $100 \mu \mathrm{L}$ of overnight cultures of the isolated strains cultured for $18 \mathrm{~h}$. Enumeration using the drop plate method was performed at $0 \mathrm{~h}, 15 \mathrm{~min}, 30 \mathrm{~min}$, and $90 \mathrm{~min}$. The controls consisted of intestinal juice or gastric juice with no digestive enzymes. The assay was performed in triplicates.

\subsection{Statistical Analysis}

All experiments were carried out in triplicate. Results were log-transformed. Graph pad Prism 8 was used to perform statistical analysis. A $p$-value $<0.05$ was considered to be significant. One-way ANOVA was used to compare control and treatment samples in the bile salt tolerance test. A paired $t$-test was used to compare control to treatment samples in the $\mathrm{pH}$ tolerance test. Dunnett's multiple comparisons test was used to analyze further results obtained from one-way ANOVA.

\section{Results}

\subsection{Screening and Isolation of Bioactive Strains and Characterization of Their Inhibitory Activity}

A total of 290 colonies were initially selected based on inhibition zones, from all four intestinal tracts obtained from a local slaughterhouse. Screening for the presence of Salmonella was carried out on MacConkey agar plates, and all the tested intestines were most likely free from Salmonella infection in view of no enrichment step that was followed. The samples were first screened by a spot-on lawn method (data not shown). Of the initial 290 colonies, the number of active isolated strains were narrowed down to 72 isolates that showed activity against $S$. Abony NCTC 6017. This step was followed by another round of screening using agar well diffusion, which narrowed down our active colonies from 72 to 55 isolates showing strong inhibition of S. Abony NCTC 6017. Next, we tested the cell-free supernatants (CFS) of the 55 isolates against C. perfringens ATCC 13124, S. Abony NCTC 6017, S. enterica serovar Typhimurium ATCC 14028, S. enterica serovar Choleraesuis ATCC 10708, and E. coli ATCC 25922. Figure 1 illustrates the inhibition of indicator strains by some selected strains' CFS, while the inhibitions' diameter of active strains is summarized in Table 1. As shown in Figure 2, the CFS of colonies UO.C025, UO.C027, UO.C031, UO.C003, and UO.C018 induced a dose-dependent inhibition of $S$. Typhimurium ATCC 14028 over $24 \mathrm{~h}$ of incubation. The CFS of the five strains had similar antimicrobial potency and completely inhibited the growth of Salmonella at $1 \times, \frac{1}{2} \times$, and $\frac{1}{4} \times$, while it induced partial inhibition at higher dilutions. 

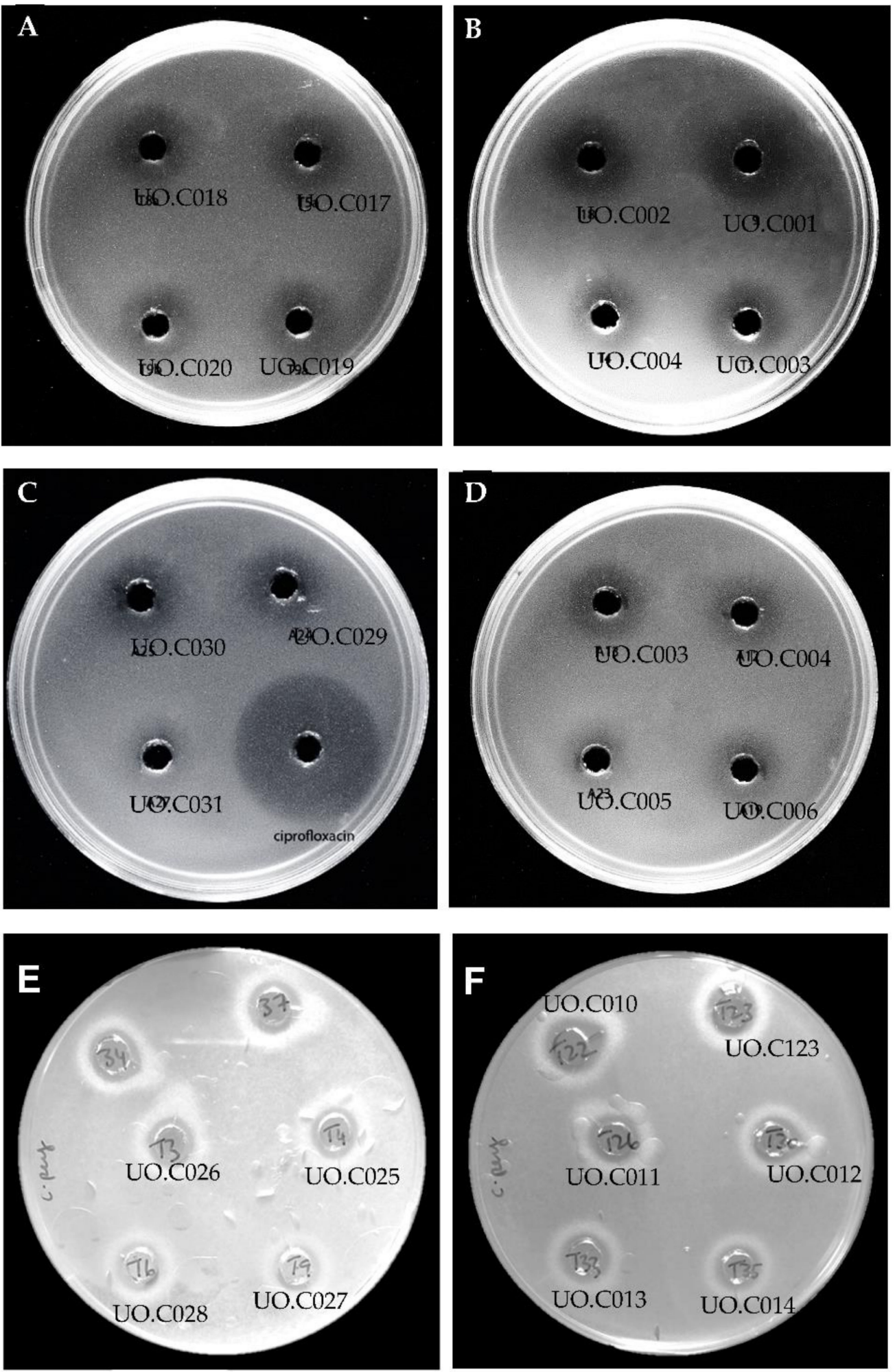

Figure 1. Agar well diffusion assay illustrating the growth inhibition of Salmonella Typhimurium ATCC 14028 (A-D) and Clostridium perfringens ATCC 13124 (E,F) by cell-free supernatants extracted from the isolated strains. 
Table 1. Determining the diameter of indicator strain inhibition by cell-free supernatants extracted from bioactive isolated strains in this study.

\begin{tabular}{|c|c|c|c|c|c|}
\hline \multirow[b]{2}{*}{ Strains ID } & \multicolumn{5}{|c|}{ Inhibition Zone (mm) } \\
\hline & $\begin{array}{c}\text { S. Abony NCTC } \\
6017\end{array}$ & $\begin{array}{l}\text { S. Typhimurium } \\
\text { ATCC } 14028\end{array}$ & $\begin{array}{l}\text { S. Choleraesuis } \\
\text { ATCC } 10708\end{array}$ & $\begin{array}{c}\text { E. coli ATCC } \\
25922\end{array}$ & $\begin{array}{l}\text { C. perfringens } \\
\text { ATCC } 13124\end{array}$ \\
\hline UO.C001 & 15 & 12 & 14 & 10 & 10 \\
\hline UO.C002 & 14 & 15 & 11 & 10 & 12 \\
\hline UO.C003 & 13 & 16 & 15 & 10 & 12 \\
\hline UO.C004 & 12 & 15 & 10 & 10 & 11 \\
\hline UO.C005 & 13 & 15 & 10 & 6 & 11 \\
\hline UO.C006 & 13 & 15 & 11 & 10 & 11 \\
\hline UO.C007 & 14 & 14 & 13 & 10 & 14 \\
\hline UO.C008 & 11 & 15 & 10 & 10 & 12 \\
\hline UO.C009 & 10 & 14 & 13 & 9 & 11 \\
\hline UO.C010 & 15 & 12 & 11 & 10 & 12 \\
\hline UO.C011 & 14 & 14 & 11 & 10 & 12 \\
\hline UO.C012 & 15 & 13 & 10 & 6 & 10 \\
\hline UO.C013 & 14 & 15 & 14 & 9 & 11 \\
\hline UO.C014 & 14 & 14 & 10 & 9 & 11 \\
\hline UO.C015 & 13 & 15 & 13 & 7 & 10 \\
\hline UO.C016 & 13 & 15 & 13 & 7 & 12 \\
\hline UO.C017 & 15 & 14 & 10 & 7 & 11 \\
\hline UO.C018 & 13 & 15 & 10 & 8 & 10 \\
\hline UO.C019 & 12 & 13 & 10 & 7 & 11 \\
\hline UO.C020 & 13 & 15 & 10 & 8 & 11 \\
\hline UO.C021 & 12 & 15 & 15 & - & 14 \\
\hline UO.C022 & - & 12 & 15 & - & 13 \\
\hline UO.C023 & - & 14 & 14 & 0.7 & 13 \\
\hline UO.C024 & - & 12 & 14 & - & 13 \\
\hline UO.C025 & 11 & 13 & 14 & - & 13 \\
\hline UO.C026 & - & 12 & 17 & - & 14 \\
\hline UO.C027 & 11 & 13 & 15 & 0.9 & 14 \\
\hline UO.C028 & - & 12 & 14 & - & 14 \\
\hline UO.C029 & - & 16 & 13 & 0.8 & 14 \\
\hline UO.C030 & - & 14 & 14 & - & 14 \\
\hline UO.C031 & - & 14 & 13 & - & 14 \\
\hline UO.C112 & 10 & 13 & 10 & 7 & 9 \\
\hline UO.C121 & 10 & 12 & 9 & 7 & 8 \\
\hline UO.C123 & 11 & 13 & 12 & 6 & 11 \\
\hline UO.C124 & 12 & 16 & - & 10 & 7 \\
\hline UO.C134 & 10 & 19 & - & 10 & 8 \\
\hline UO.C137 & 11 & 15 & 13 & 10 & 10 \\
\hline UO.CA05 & - & 14 & 12 & - & 12 \\
\hline UO.CA22 & - & 13 & 10 & - & 13 \\
\hline
\end{tabular}


A

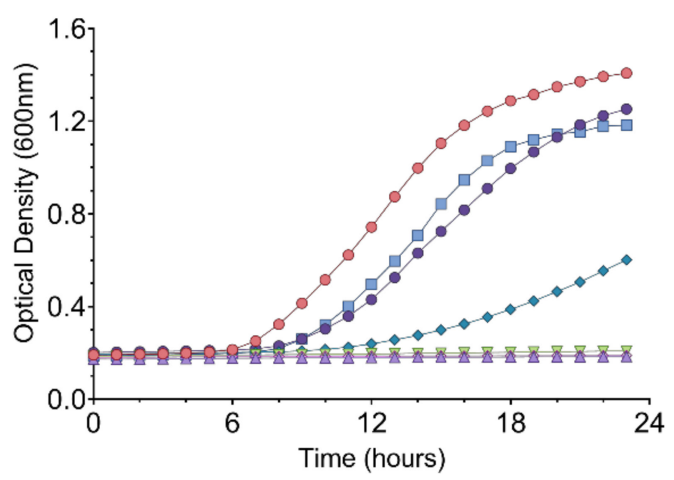

C

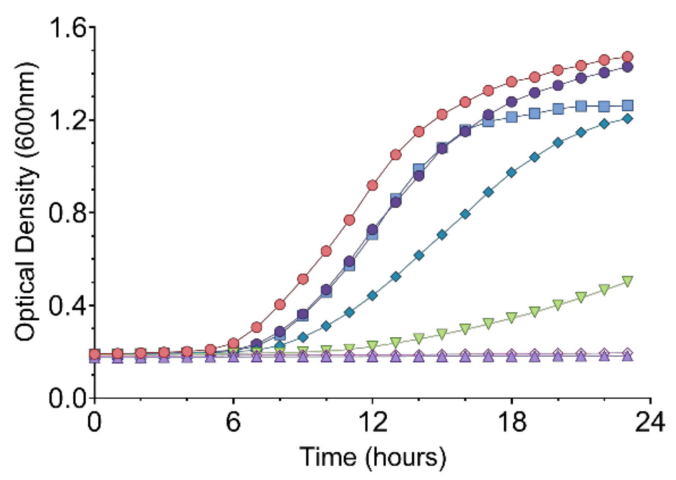

B

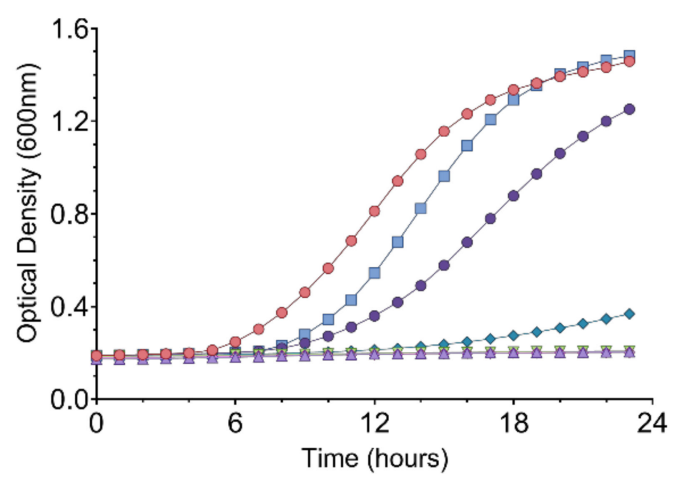

D

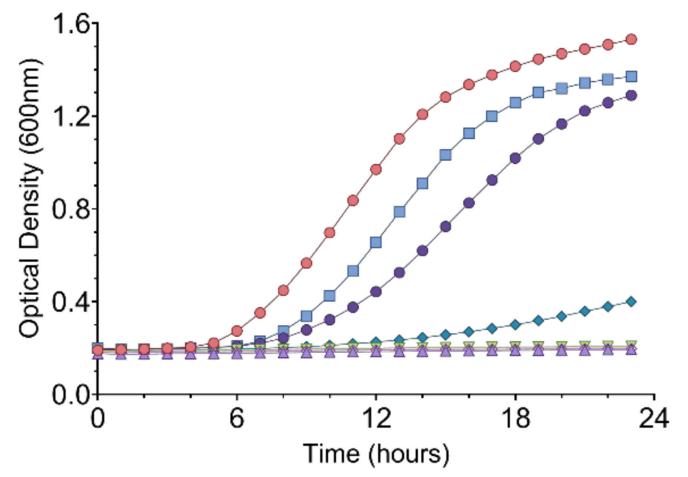

E

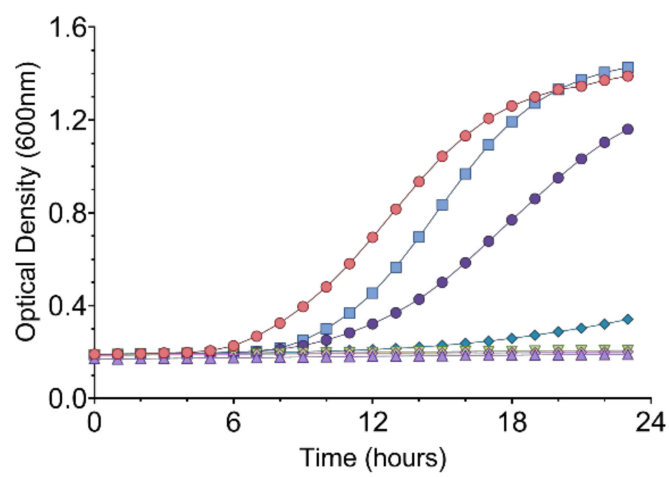

Figure 2. Dose-response growth inhibition of Salmonella Typhimurium ATCC 14028 by cell-free supernatants from strains UO.C025 (A), UO.C027 (B), UO.C031 (C), UO.C003 (D), and UO.C018 (E). Tested concentrations are $1 \times$ (purple triangle), 1/2 (magenta diamond), 1/4 (triangle), 1/8 (diamond), 1/16 (dark purple circle), 1/32 (blue square), and 0 (negative control, red circle).

\subsection{Molecular Identification of Isolated Bioactive Strains}

The 16S rRNA of the most active strains (31) was sequenced. The isolates belonged to Ligilactobacillus salivarius $(n=19)$, Ligilactobacillus agilis $(n=1)$, Lactobacillus johnsonii $(n=7)$, Lactobacillus kitasatonis $(n=1)$, Lactobacillus sp. $(n=2)$, and uncultured bacterium $(n=1)$. Among the identified strains, UO.C003 was identified as Ligilactobacillus salivarius, 
UO.C018 as Ligilactobacillus agilis, UO.C025 as Lactobacillus kitasatonis, and UO.C027 as Ligilactobacillus salivarius (Table 2). The molecular identification of the strain UO.C031 revealed a new unclassified bacterium with partial similarity to Lactobacillus gallinarum.

Table 2. Molecular identification of isolated bioactive strains by $16 \mathrm{~S}$ rRNA sequencing. Strains in bold represent the five most potent strains that were further characterized for their probiotic potential.

\begin{tabular}{|c|c|c|c|c|}
\hline Chicken & Location/Type & Anatomy & Sample Id & Identity \\
\hline$\# 3$ & mucosal/aerobic & ceca & UO.C001 & Ligilactobacillus salivarius \\
\hline$\# 3$ & mucosal/aerobic & ceca & UO.C002 & Ligilactobacillus salivarius \\
\hline$\# 4$ & mucosal/aerobic & ceca & UO.C003 & Ligilactobacillus salivarius \\
\hline$\# 4$ & mucosal/aerobic & ceca & UO.C004 & Ligilactobacillus salivarius \\
\hline$\# 4$ & mucosal/aerobic & ceca & UO.C005 & Lactobacillus johnsonii \\
\hline$\# 4$ & mucosal/aerobic & ceca & UO.C006 & Lactobacillus sp. \\
\hline$\# 4$ & mucosal/aerobic & ceca & UO.C007 & Ligilactobacillus salivarius \\
\hline$\# 4$ & mucosal/aerobic & ceca & UO.C008 & Ligilactobacillus salivarius \\
\hline$\# 4$ & mucosal/aerobic & ceca & UO.C009 & Ligilactobacillus salivarius \\
\hline$\# 4$ & mucosal/aerobic & ceca & UO.C010 & Ligilactobacillus salivarius \\
\hline$\# 4$ & mucosal/aerobic & ceca & UO.C011 & Ligilactobacillus salivarius \\
\hline$\# 4$ & mucosal/aerobic & ceca & UO.C012 & Lactobacillus sp. \\
\hline$\# 4$ & mucosal/aerobic & ceca & UO.C013 & Ligilactobacillus salivarius \\
\hline$\# 4$ & mucosal/aerobic & ceca & UO.C014 & Lactobacillus johnsonii \\
\hline$\# 4$ & mucosal/aerobic & ceca & UO.C015 & Ligilactobacillus salivarius \\
\hline$\# 4$ & mucosal/aerobic & ceca & UO.C016 & Ligilactobacillus salivarius \\
\hline$\# 1$ & mucosal/aerobic & ceca & UO.C017 & Ligilactobacillus salivarius \\
\hline$\# 1$ & mucosal/aerobic & ceca & UO.C018 & Ligilactobacillus agilis \\
\hline$\# 1$ & mucosal/aerobic & ceca & UO.C019 & Ligilactobacillus salivarius \\
\hline$\# 1$ & mucosal/aerobic & ceca & UO.C020 & Ligilactobacillus salivarius \\
\hline$\# 4$ & mucosal/anaerobic & ceca & UO.C021 & Lactobacillus johnsonii \\
\hline$\# 4$ & mucosal/anaerobic & ceca & UO.C022 & Lactobacillus johnsonii \\
\hline$\# 4$ & mucosal/anaerobic & ceca & UO.C023 & Ligilactobacillus salivarius \\
\hline$\# 4$ & mucosal/anaerobic & ceca & UO.C024 & Lactobacillus johnsonii \\
\hline$\# 4$ & mucosal/anaerobic & ceca & UO.C025 & Lactobacillus kitasatonis \\
\hline$\# 4$ & mucosal/anaerobic & ceca & UO.C026 & Ligilactobacillus salivarius \\
\hline$\# 4$ & mucosal/anaerobic & ceca & UO.C027 & Ligilactobacillus salivarius \\
\hline$\# 3$ & mucosal/anaerobic & ceca & UO.C028 & Lactobacillus johnsonii \\
\hline$\# 3$ & mucosal/anaerobic & ceca & UO.C029 & Ligilactobacillus salivarius \\
\hline$\# 3$ & mucosal/anaerobic & ceca & UO.C030 & Lactobacillus johnsonii \\
\hline$\# 3$ & mucosal/anaerobic & ceca & UO.C031 & UNCULTURED bacterium \\
\hline
\end{tabular}

\subsection{Draft Whole-Genome Sequence and Bacteriocin Genome-Mining of the Selected Candidates}

Kraken2 confirmed the 16S rRNA-based identity of UO.C003, UO.C018, and UO.C027 where $92 \%, 73 \%$, and $93 \%$ of the generated reads were assigned to L. salivarius, L. agilis, and L. salivarius, respectively. The generated reads of UO.C025 and UO.C031 were assigned to the genus Lactobacillus with $21 \%$ and $23 \%$ of the reads with no hits in the database. 
Table 3 summarizes the genomic information of these strains and their closest phylogenetic neighbor generated by RAST. Table 4 shows, in detail, all the bacteriocin genes that were identified, their location, and their similarity to BLAST search using both BAGEL4 and antiSMASH. BAGEL4 was able to identify the presence of bacteriocin genes in four of the five isolated strains with enterolysin A being the commonly identified bacteriocin gene. Lactobacillus kitasatonis also had Helveticin-J genes, and Ligilactobacillus salivarius had salivaricin_P_chain_b genes. Likewise, antiSMASH identified lanthipeptide genes in Lactobacillus kitasatonis and Linocin_M18 genes in Lactobacillus gallinarum. The Ligilactobacillus salivarius strain had salivaricin CRL1328 $\alpha$ peptide/salivaricin CRL1328 $\beta$ peptide with $75 \%$ of genes showing a similarity. The PHAge Search Tool Enhanced Release (PHASTER) (Arndt et al., 2016) identified a number of prophage regions in the sequenced genome that ranged from 0 to 3 regions per genome, as summarized in Table 5.

Table 3. Whole genome draft sequence overview as annotated by Rapid Annotation using Subsystem Technology (RAST) server.

\begin{tabular}{|c|c|c|c|c|c|c|c|c|c|c|}
\hline Strains & $\begin{array}{l}\text { 16S rRNA } \\
\text { Identity }\end{array}$ & $\begin{array}{c}\text { Genome } \\
\text { Size } \\
\text { (bp) }\end{array}$ & $\begin{array}{c}\text { GC } \\
\text { Content }\end{array}$ & Contig & N50 & L50 & $\begin{array}{c}\text { Number } \\
\text { of Sub- } \\
\text { systems }\end{array}$ & $\begin{array}{l}\text { Number of } \\
\text { Coding } \\
\text { Sequences }\end{array}$ & $\begin{array}{l}\text { Number } \\
\text { of RNAs }\end{array}$ & Closest Neighbour \\
\hline UO.C003 & L. salivarius & $2,024,427$ & 32.7 & 100 & 176765 & 4 & 211 & 1994 & 76 & $\begin{array}{l}\text { L. salivarius ATCC } \\
11741\end{array}$ \\
\hline UO.C018 & L. agilis & $2,345,855$ & 41.0 & 110 & 116853 & 7 & 214 & 2346 & 92 & $\begin{array}{c}\text { L. salivarius ATCC } \\
11741\end{array}$ \\
\hline UO.C025 & L. kitasatonis & $1,975,848$ & 37.4 & 163 & 47569 & 16 & 189 & 2077 & 58 & $\begin{array}{l}\text { L. delbrueckii subsp. } \\
\text { bulgaricus ATCC } 11842\end{array}$ \\
\hline UO.C027 & L. salivarius & $1,848,796$ & 32.8 & 76 & 261149 & 2 & 212 & 1087 & 70 & $\begin{array}{c}\text { L. salivarius ATCC } \\
11741\end{array}$ \\
\hline UO.C031 & L. gallinarum & $2,014,858$ & 36.5 & 145 & 51519 & 15 & 192 & 2092 & 74 & L. acidophilus NCFM \\
\hline
\end{tabular}

Table 4. Overview of all the bacteriocin genes that were identified, their location, and their similarity to BLAST search using both antiSMASH and BAGEL4.

\begin{tabular}{|c|c|c|c|c|c|c|c|}
\hline Strain & BLAST Identity & Identified Bacteriocin & Region & From & To & Similarity & Database \\
\hline UO.C003 & L. salivarius & $\begin{array}{l}\text { salivaricin CRL1328 } \alpha \text { peptide/ } \\
\text { salivaricin CRL1328 } \beta \text { peptide }\end{array}$ & 28.1 & 27,593 & 46,844 & $75 \%$ & antiSMASH \\
\hline UO.C025 & L. kitasatonis & Lanthipeptide & 29.1 & 1 & 19,666 & & antiSMASH \\
\hline UO.C031 & L. gallinarum & Linocin_M18 & 15.1 & 33,984 & 44,931 & & antiSMASH \\
\hline Strain & BLAST Identity & Identified Bacteriocin & NODE & From & To & Blast Result & Database \\
\hline \multirow{4}{*}{ UO.C003 } & \multirow{4}{*}{ L. salivarius } & 63.3, Enterolysin A & 8 & 149,321 & 169,768 & $49 \%$ & \multirow{4}{*}{ BAGEL4 } \\
\hline & & 153.2, MR10B & 15 & 3548 & 19,814 & $85.33 \%$ & \\
\hline & & 213.2, Salivaricin_P_chain_b & 83 & 18,395 & 51,832 & $58.54 \%$ & \\
\hline & & E64.3, Enterolysin A & 1 & 165,542 & 186,031 & $38.93 \%$ & \\
\hline \multirow{4}{*}{ UO.C025 } & \multirow{4}{*}{ L. kitasatonis } & 70.3, Helveticin J & 60 & 3635 & 15,615 & $37.15 \%$ & \multirow{4}{*}{ BAGEL4 } \\
\hline & & 62.3, Enterolysin A & 93 & 1 & 14,236 & $62.73 \%$ & \\
\hline & & 64.3, Enterolysin A & 93 & 11,342 & 23,788 & $81.22 \%$ & \\
\hline & & 6.3 Helveticin J & 190 & 39,656 & 56,375 & $90.20 \%$ & \\
\hline
\end{tabular}

\subsection{Probiotic Potential of Bioactive Strains}

The breakpoints cut-off values were determined from the European Food Safety Authority (EFSA) panel on additives and products or substances used in animal feed (FEEDAP) [34]. L. agilis UO.C018 and L. kitasatonis UO.C025 breakpoint cut-off values were assumed to be the same as L. salivarius. All four are facultative homofermentative species. All tested strains showed susceptibility to ampicillin, with L. kitasatonis UO.C025 and uncultured bacterium UO.C031 showing susceptibility to vancomycin as well. All isolates showed resistance to gentamycin, streptomycin, erythromycin, tetracycline, and chloramphenicol (Table 6). 
Table 5. Overview of prophage regions identified in the draft genomes of the selected bioactive strains by the PHAge Search Tool Enhanced Release (PHASTER) (Arndt et al., 2016).

\begin{tabular}{|c|c|c|c|c|}
\hline Strain & $\begin{array}{c}\text { Number of } \\
\text { Prophage Regions }\end{array}$ & Region Length & Completeness & Most Common Phage \\
\hline UO.C025 & 0 & & & \\
\hline UO.C027 & 1 & $21.3 \mathrm{~kb}$ (16 protein) & incomplete & PHAGE_Staphy_SPbeta_like_NC_029119 \\
\hline UO.C031 & 2 & $\begin{array}{l}23.5 \mathrm{~kb} \text { (35 protein }) \\
28.1 \mathrm{~kb} \text { (32 protein }) \\
59.5 \mathrm{~kb} \text { (63 protein) }\end{array}$ & $\begin{array}{l}\text { incomplete } \\
\text { incomplete } \\
\text { intact }\end{array}$ & $\begin{array}{l}\text { PHAGE_Lactob_Lj965_NC_005355 } \\
\text { PHAGE_Lactob_LBR48_NC_027990 } \\
\text { PHAGE_Lactob_CL1_NC_028888 }\end{array}$ \\
\hline UO.C003 & 3 & $\begin{array}{l}25.3 \mathrm{~kb} \text { ( } 26 \text { protein }) \\
16.9 \mathrm{~kb} \text { ( } 20 \text { protein })\end{array}$ & $\begin{array}{l}\text { incomplete } \\
\text { questionable }\end{array}$ & $\begin{array}{l}\text { PHAGE_Lactob_PLE2_NC_031036 } \\
\text { PHAGE_Paenib_Shelly_NC_041909 }\end{array}$ \\
\hline UO.C018 & 1 & $57.2 \mathrm{~kb}$ (70 proteins) & intact & PHAGE_Lactob_Sha1_NC_019489 \\
\hline
\end{tabular}

Table 6. Minimum inhibitory concentration (MIC in $\mu \mathrm{g} / \mathrm{mL}$ ) and interpretation of selected strains.

\begin{tabular}{|c|c|c|c|c|c|c|c|c|c|c|c|}
\hline \multirow{2}{*}{ Antibiotics } & \multirow{2}{*}{ Breakpoints } & \multicolumn{2}{|r|}{ UO.C003 } & \multicolumn{2}{|r|}{ UO.C018 } & \multicolumn{2}{|r|}{ UO.C025 } & \multicolumn{2}{|r|}{ UO.C027 } & \multicolumn{2}{|r|}{ UO.C031 } \\
\hline & & MIC & Susceptibility & MIC & Susceptibility & MIC & Susceptibility & MIC & Susceptibility & MIC & Susceptibility \\
\hline Ampicillin & 4 & 2 & $S$ & 2 & $S$ & 2 & $S$ & 4 & $S$ & 2 & $S$ \\
\hline Vancomycin & $n \cdot r$ & $>32$ & $\mathrm{R}$ & $>32$ & $\mathrm{R}$ & 4 & $S$ & $>32$ & $\mathrm{R}$ & 4 & $S$ \\
\hline Gentamycin & 16 & $>32$ & $\mathrm{R}$ & $>32$ & $\mathrm{R}$ & $>32$ & $\mathrm{R}$ & $>32$ & $\mathrm{R}$ & $>32$ & $\mathrm{R}$ \\
\hline Streptomycin & 64 & $>32$ & $\mathrm{R}$ & $>32$ & $\mathrm{R}$ & 128 & $\mathrm{R}$ & $>32$ & $\mathrm{R}$ & 128 & $\mathrm{R}$ \\
\hline Erythromycin & 1 & 2 & $\mathrm{R}$ & 4 & $\mathrm{R}$ & 1 & $S$ & 4 & $\mathrm{R}$ & 2 & $\mathrm{R}$ \\
\hline Tetracycline & 8 & $>32$ & $\mathrm{R}$ & $>32$ & $\mathrm{R}$ & $>32$ & $\mathrm{R}$ & $>32$ & $\mathrm{R}$ & 8 & $S$ \\
\hline Chloramphenicol & 4 & 16 & $\mathrm{R}$ & 16 & $\mathrm{R}$ & 16 & $\mathrm{R}$ & $>32$ & $\mathrm{R}$ & 16 & $\mathrm{R}$ \\
\hline
\end{tabular}

The selected strains were also subjected to acidic $\mathrm{pH}$ and bile salts under simulated gastric intestinal and juices to determine the viability of our isolated strains under harsh gastrointestinal conditions. For the $\mathrm{pH}$ tolerance test, simulated gastric juice with a $\mathrm{pH}$ of 2.6 and 4.5 was selected to represent the physiological $\mathrm{pH}$ of the gizzard and the crop segments, respectively. The selected strains had a high survival rate at both $\mathrm{pH} 4.5$ and 2.6 with a respective range of $88.97 \%-99.33 \%$ and $76.80 \%-93.98 \%$ (Figure 3 ). The strains L. kitasatonis UO.C025, L. salivarius UO.C027, and uncultured bacterium UO.C031 exhibited the highest survival rate, while L. agilis UO.C018 was the most sensitive to the two tested $\mathrm{pH}$ values. For the bile salts' tolerance test, varying concentrations of oxgall bile salts were added to the simulated intestinal juice, containing pancreatin. The bile salts concentrations tested included $0.1 \%, 0.2 \%, 0.3 \%, 0.4 \%, 0.6 \%, 0.8 \%, 1 \%$, and $1.5 \%$. The lowest concentration to show growth after at least $3 \mathrm{~h}$ was $0.3 \%$ bile salts, while no growth of tested strains was observed at higher concentrations. The difference between the control and the treated samples was statistically significant ( $p$-value $<0.05$, Figure 4$)$. 


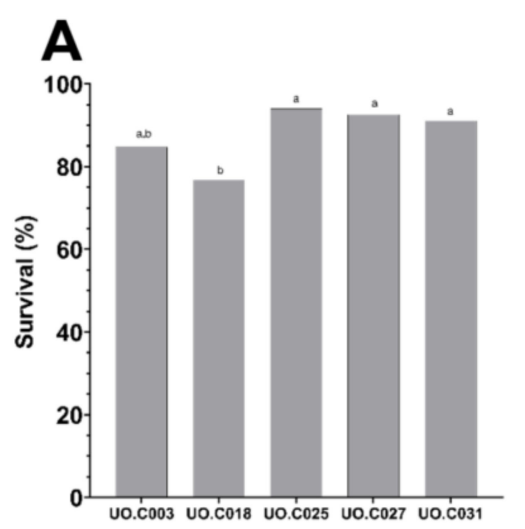

Strains

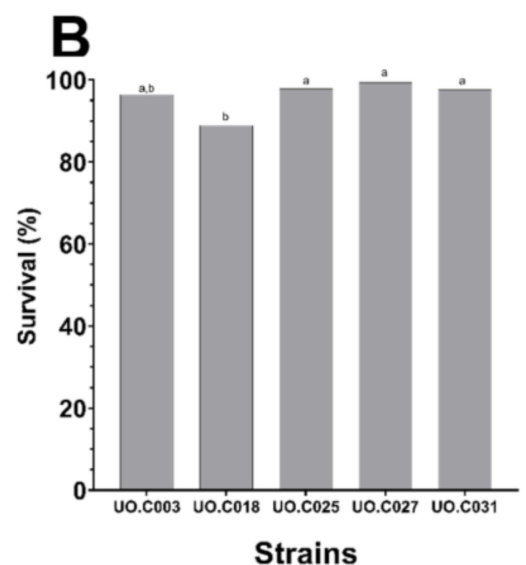

Strains

Figure 3. Percentage of survival of selected bioactive strains under acidic $\mathrm{pH} 2.6$ (Gizzard, A) and pH 4.5 (Crop, B) in a simulated gastric juice. a and b labels the strains that exhibit significant differences in their survival at each $\mathrm{pH}$.

A

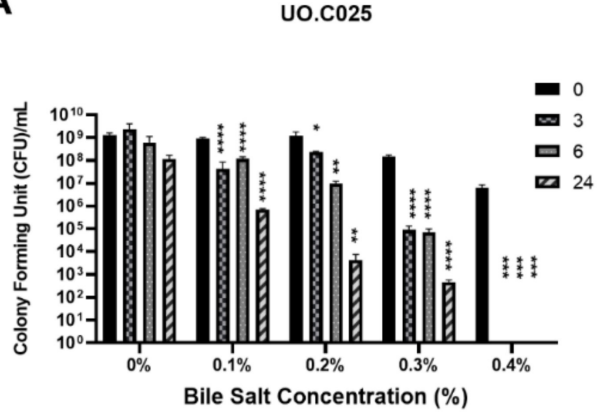

C

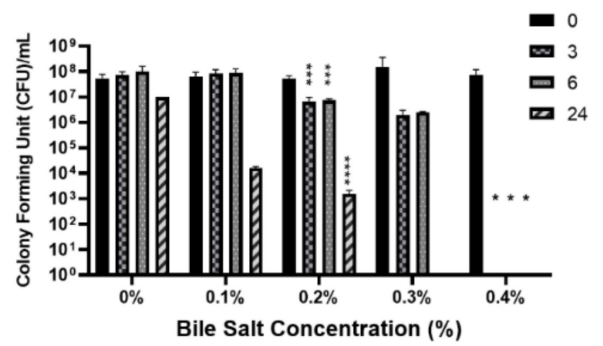

E

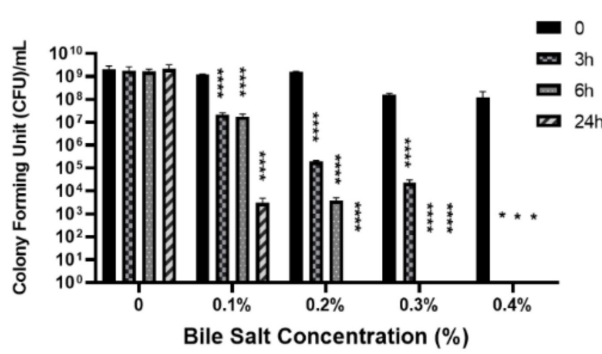

B

UO.C027

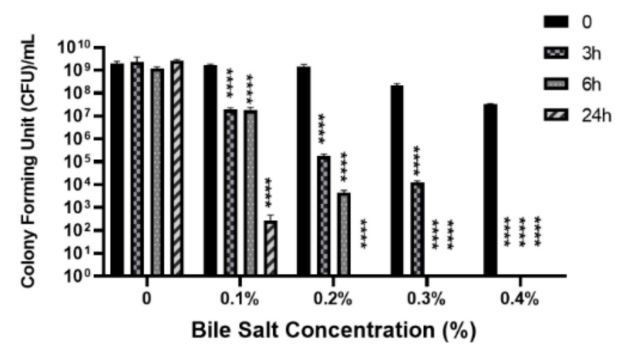

D

Uo.c003

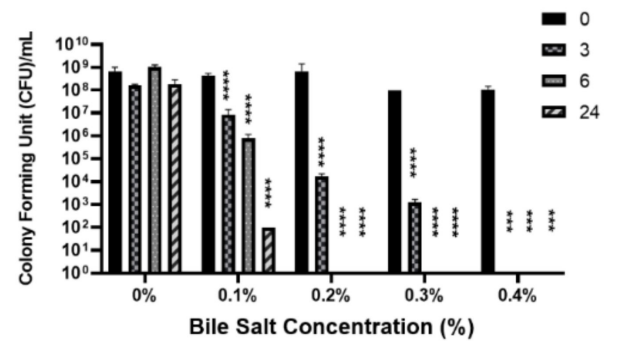

Figure 4. Isolated strains tested for bile salt tolerance in simulated intestinal juice at times $0,3,6$, and $24 \mathrm{~h}$. One-way ANOVA followed by Dunnett's multiple comparison test were used for statistical comparison of the difference between each time point and the zero time. ${ }^{*} p<0.05,{ }^{* *} p<0.01$, ${ }^{* * *} p<0.001,{ }^{* * * *} p<0.0001$ as compared to the zero time of each concentration. 


\section{Discussion}

Probiotics have been shown to modulate the immune system, increase the proliferation of beneficial commensal bacteria, increase nutrient absorption, and, hence, increase feed conversion efficiency, and increase body weight [12]. For some probiotics, such as Lactobacilli, these beneficial properties are due to the production of bacteriocins and short-chain fatty acids. Lactobacilli and other anaerobic bacteria are found to adhere to the epithelium of the intestinal tract, which is also abundant with Bifidobacterium sp., Enterococcus faecium, and Pediococcus spp., with the ceca having the highest concentration of anaerobic bacteria [35]. FAO and WHO recommend that a probiotic be able to survive the passage, adhere, and multiply through the GIT, be a Gram-positive organism, show measurable health benefits, and have a defined dosage duration [36,37]. In this study, we aimed to isolate potential probiotic bacterial strains from the cecum mucosa from broiler chickens that could reduce Salmonella enterica and C. perfringens, which are important foodborne pathogens. We chose to target the mucosa of the intestinal tract rather than the lumen contents because the commensal strains are already ideally suited to that specific environment via adhesion and competitive exclusion, and, therefore, have a head start at potential probiotic properties [38].

To accelerate the isolation and screening of potential probiotic strains, instead of allowing the colonies to grow on MRS agar plates for $24-48 \mathrm{~h}$ as per a standard protocol, we adapted the protocol to simultaneously allow the growth of colonies while they exhibit inhibition zones on the agar plates. A total of 290 presumably active isolates, that are aerobic and anaerobic, from four intestines were selected based on the presence of inhibition zones in the initial double agar method. These colonies were further screened using the spot-on lawn method and, then, the agar well diffusion assay, resulting in 55 inhibitory strains against Salmonella. Additionally, dose-dependent inhibition of Salmonella over $24 \mathrm{~h}$ was observed in all the tested strains, which might be attributed to the presence of short-chain fatty acids (lactic acid, propionate, butyrate, and acetate), hydrogen peroxide, or bacteriocinlike compounds. For instance, selected bioactive strains belong to the lactobacilli group, members of the lactic acid bacteria, a broadly defined group characterized by lactic acid production as a sole or main end product of carbohydrate fermentation [39].

The predominant identity of the isolated strains was from L. salivarius, followed by L. johnsonii. We also isolated and identified other lactobacilli strains belonging to L. agilis, L. kitasatonis, Lactobacillus sp., and a new uncultured bacterium. This is consistent with findings that the L. acidophilus group (L. crispatus, L. gallinarum, and L. johnsonii), L. agilis, L. salivarius, and L. reuteri are commonly present Lactobacilli in chicken intestines [40]. From among the L. acidophilus group, it was found that L. salivarius was the predominant species among the intestinal microbiota of young chickens, which is consistent with what we found from our isolation results [40]. L. kitasatonis was originally isolated from the intestinal tract of chickens in Japan in 2003 [41]. Since then, L. kitasatonis has been isolated from dogs in Japan [42], geese feces in Poland [43], and pig feces in Italy [44]. Different species are found along the chicken intestinal tract. Lactobacilli species are found in high concentrations in the upper GIT but also in the ileum than cecum [38]. It has also been reported that L. salivarius and L. johnsonii are found in a higher percentage in the ileal mucosa when compared to cecal mucosa or cecal lumen, but there was no statistical difference between them [38]. The same researchers found L. salivarius to be a predominant species along with the entire GIT, which is consistent with other reports that, in 36-days-old chickens, L. salivarius has a higher percentage of being isolated from both the ileum and cecum [38].

All isolated strains showed susceptibility to ampicillin but resistance to vancomycin, gentamycin, streptomycin, erythromycin, tetracycline, and chloramphenicol. Lactobacilli are considered non-pathogenic and are widely used as probiotics and starter cultures for various foods, and are supported by a long history of safe usage [45]. Despite their safety status, many Lactobacillus species have been reported as intrinsically resistant to antibiotics, such as vancomycin, gentamycin, kanamycin, streptomycin, and ciprofloxacin, but susceptible to penicillin and $\beta$-lactams [45]. Our whole genome sequencing (WGS) 
results showed that our isolated strains have the capability to produce bacteriocins and lack plasmids, toxins, adhesion toxins, and transposable elements, indicating that their resistance profiles are chromosome-mediated.

Resistance to harsh gastrointestinal conditions is important during probiotic selection. Our selected strains exhibited a high survival rate at acidic conditions mimicking the physiological $\mathrm{pH}$ of crop and gizzard, indicating their suitability as potential probiotics since they would be able to survive passage through the gastrointestinal tract (GIT) and attach to the mucosa via competitive exclusion (the strains were originally isolated from the mucosa of the ceca). Our results showed superior results to those reported by Reference [46], whose L. salivarius and L. kitasatonis strains could not survive the acid tolerance test after one-hour incubation. Our selected strains were able to survive the tested bile salt concentration of $0.3 \%$ for at least $3 \mathrm{~h}$. Similar results were obtained by Reference [46], who observed that only a single L. kitasatonis strain was able to survive growth in $0.3 \%$ oxgall bile salts. The actual bile salt concentration in chicken duodenum, jejunum, and cecum is $1.75 \mathrm{mg} / \mathrm{mL}, 7 \mathrm{mg} / \mathrm{mL}$, and $0.085 \mathrm{mg} / \mathrm{mL}$, respectively [47]. Our strains were able to survive at the tested oxgall concentration of $3 \mathrm{mg} / \mathrm{mL}$, indicating that they would survive passage to the duodenum and ceca if well formulated.

\section{Conclusions}

The present study provides evidence that lactobacilli strains isolated from chicken caecal mucosa harbor bacteriocin genes and produce inhibitory substances against Salmonella enterica and Clostridium perfringens. While L. salivarius UO.C003, L. agilis UO.C018, L. kitasatonis UO.C025, L. salivarius UO.C027, and a new uncultured bacterium presented some interesting probiotic features. A further investigation is required toward their application as novel probiotic strains in the poultry industry.

Author Contributions: A.L. and R.H. conceived and designed the study. A.L., W.M., and Y.A.C. acquired, analyzed, and interpreted the data. A.L., W.M., and R.H. drafted or revised the article. All authors have read and agreed to the published version of the manuscript.

Funding: This study was supported by a grant from the Ontario Ministry of Agriculture, Food and Rural Affairs (OMAFRA) [No. OAF-2019-100380].

Institutional Review Board Statement: Animal tissues were obtained from an accredited commercial abattoir, and ethical approval was not sought for the present study.

Informed Consent Statement: Not applicable.

Data Availability Statement: The whole genome sequence of the five tested strains will be deposited at GenBank under the BioProject accession number PRJNA685183.

Conflicts of Interest: The authors declare no conflict of interest.

\section{References}

1. Hofacre, C.L.; Smith, J.A.; Mathis, G.F. An optimist's view on limiting necrotic enteritis and maintaining broiler gut health and performance in today's marketing, food safety, and regulatory climate. Poult. Sci. 2018, 97, 1929-1933. [CrossRef]

2. Liu, L.; Lin, L.; Zheng, L.; Tang, H.; Fan, X.; Xue, N.; Li, M.; Liu, M.; Li, X. Cecal microbiome profile altered by Salmonella enterica, serovar Enteritidis inoculation in chicken. Gut Pathog. 2018, 10, 34. [CrossRef]

3. Food, E.; Authority, S. EFSA The European Union summary report on antimicrobial resistance in zoonotic and indicator bacteria from humans, animals and food in 2016. EFSA J. 2018, 16. [CrossRef]

4. CDC Outbreaks Involving Salmonella I CDC. Available online: https:/ /www.cdc.gov/salmonella/outbreaks.html (accessed on 7 November 2018).

5. Center for Disease Control and Prevention Serotypes and the Importance of Serotyping Salmonella I Salmonella Atlas I Reports and Publications I Salmonella I CDC. Available online: https: / /www.cdc.gov/salmonella/reportspubs/salmonella-atlas/serotypingimportance.html\#three (accessed on 7 November 2018).

6. CDC Clostridium Perfringens. Available online: https://www.cdc.gov/foodsafety/diseases/clostridium-perfringens.html (accessed on 13 September 2020).

7. Immerseel, F.V.; Buck, J.D.; Pasmans, F.; Huyghebaert, G.; Haesebrouck, F.; Ducatelle, R. Clostridium perfringens in poultry: An emerging threat for animal and public health. Avian Pathol. 2004, 33, 537-549. [CrossRef] 
8. Oakley, B.B.; Lillehoj, H.S.; Kogut, M.H.; Kim, W.K.; Maurer, J.J.; Pedroso, A.; Lee, M.D.; Collett, S.R.; Johnson, T.J.; Cox, N.A. The chicken gastrointestinal microbiome. FEMS Microbiol. Lett. 2014, 360, 100-112. [CrossRef]

9. Food and Drug Administration Antimicrobial Resistance Information from FDA. Available online: https://www.fda.gov/ EmergencyPreparedness/Counterterrorism/MedicalCountermeasures/MCMIssues/ucm620149.htm (accessed on 7 November 2018).

10. Government of Canada Notice to Stakeholders: Update on Collaborative Efforts to Promote the Prudent Use of Medically-Important Antimicrobials in Animals 2018; Health Canada, Veterinary Drugs Directorate: Ottawa, ON, Canada, 2018.

11. Redondo, L.M.; Chacana, P.A.; Dominguez, J.E.; Fernandez Miyakawa, M.E. Perspectives in the use of tannins as alternative to antimicrobial growth promoter factors in poultry. Front. Microbiol. 2014, 5. [CrossRef]

12. Suresh, G.; Das, R.K.; Kaur Brar, S.; Rouissi, T.; Avalos Ramirez, A.; Chorfi, Y.; Godbout, S. Alternatives to antibiotics in poultry feed: Molecular perspectives. Crit. Rev. Microbiol. 2018, 44, 318-335. [CrossRef]

13. Angelakis, E. Weight gain by gut microbiota manipulation in productive animals. Microb. Pathog. 2017, 106, 162-170. [CrossRef]

14. Kizerwetter-Swida, M.; Binek, M. Protective effect of potentially probiotic Lactobacillus strain on infection with pathogenic bacteria in chickens. Pol. J. Vet. Sci. 2009, 12, 15-20.

15. Jin, L.Z.; Ho, Y.W.; Abdullah, N.; Jalaludin, S. Digestive and Bacterial Enzyme Activities in Broilers Fed Diets Supplemented with Lactobacillus Cultures. Poult. Sci. 2000, 79, 886-891. [CrossRef]

16. Awad, W.A.; Böhm, J.; Razzazi-Fazeli, E.; Ghareeb, K.; Zentek, J. Effect of Addition of a Probiotic Microorganism to Broiler Diets Contaminated with Deoxynivalenol on Performance and Histological Alterations of Intestinal Villi of Broiler Chickens. Poult. Sci. 2006, 85, 974-979. [CrossRef]

17. Yang, X.; Brisbin, J.; Yu, H.; Wang, Q.; Yin, F.; Zhang, Y.; Sabour, P.; Sharif, S.; Gong, J. Selected Lactic Acid-Producing Bacterial Isolates with the Capacity to Reduce Salmonella Translocation and Virulence Gene Expression in Chickens. PLoS ONE 2014, 9 , e93022. [CrossRef]

18. Hanchi, H.; Mottawea, W.; Sebei, K.; Hammami, R. The Genus Enterococcus: Between Probiotic Potential and Safety ConcernsAn Update. Front. Microbiol. 2018, 9. [CrossRef]

19. Lauková, A.; Kandričáková, A.; Ščerbová, J. Use of bacteriocin-producing, probiotic strain Enterococcus faecium AL41 to control intestinal microbiota in farm ostriches. Lett. Appl. Microbiol. 2015, 60, 531-535. [CrossRef]

20. Ben Lagha, A.; Haas, B.; Gottschalk, M.; Grenier, D. Antimicrobial potential of bacteriocins in poultry and swine production. Vet. Res. 2017, 48, 1-12. [CrossRef]

21. Lo Verso, L.; Lessard, M.; Talbot, G.; Fernandez, B.; Fliss, I. Isolation and Selection of Potential Probiotic Bacteria from the Pig Gastrointestinal Tract. Probiot. Antimicrob. Proteins 2018, 10, 299-312. [CrossRef]

22. Hanchi, H.; Hammami, R.; Kourda, R.; Hamida, J.B.; Fliss, I. Bacteriocinogenic properties and in vitro probiotic potential of enterococci from Tunisian dairy products. Arch. Microbiol. 2014, 196, 331-344. [CrossRef]

23. Hammami, R.; Zouhir, A.; Hamida, J.B.; Neffati, M.; Vergoten, G.; Naghmouchi, K.; Fliss, I. Antimicrobial properties of aqueous extracts from three medicinal plants growing wild in arid regions of Tunisia. Pharm. Biol. 2009, 47, 452-457. [CrossRef]

24. Turner, S.; Pryer, K.M.; Miao, V.P.W.; Palmer, J.D. Investigating Deep Phylogenetic Relationships among Cyanobacteria and Plastids by Small Subunit rRNA Sequence Analysis. J. Eukaryot. Microbiol. 1999, 46, 327-338. [CrossRef]

25. Altschul, S.F.; Gish, W.; Miller, W.; Myers, E.W.; Lipman, D.J. Basic local alignment search tool. J. Mol. Biol. 1990, 215 , 403-410. [CrossRef]

26. Wood, D.E.; Salzberg, S.L. Kraken: Ultrafast Metagenomic Sequence Classification Using Exact Alignments. Genome Biol. 2014, 15, R46. [CrossRef]

27. Aziz, R.K.; Bartels, D.; Best, A.A.; DeJongh, M.; Disz, T.; Edwards, R.A.; Formsma, K.; Gerdes, S.; Glass, E.M.; Kubal, M.; et al. The RAST Server: Rapid Annotations Using Subsystems Technology. BMC Genom. 2008, 9, 75. [CrossRef]

28. Brettin, T.; Davis, J.J.; Disz, T.; Edwards, R.A.; Gerdes, S.; Olsen, G.J.; Olson, R.; Overbeek, R.; Parrello, B.; Pusch, G.D.; et al. RASTtk: A Modular and Extensible Implementation of the RAST Algorithm for Building Custom Annotation Pipelines and Annotating Batches of Genomes. Sci. Rep. 2015, 5, 8365. [CrossRef]

29. Overbeek, R.; Olson, R.; Pusch, G.D.; Olsen, G.J.; Davis, J.J.; Disz, T.; Edwards, R.A.; Gerdes, S.; Parrello, B.; Shukla, M.; et al. The SEED and the Rapid Annotation of Microbial Genomes Using Subsystems Technology (RAST). Nucleic Acids Res. 2014, 42, D206-D214. [CrossRef]

30. Blin, K.; Shaw, S.; Steinke, K.; Villebro, R.; Ziemert, N.; Lee, S.Y.; Medema, M.H.; Weber, T. AntiSMASH 5.0: Updates to the Secondary Metabolite Genome Mining Pipeline. Nucleic Acids Res. 2019, 47, W81-W87. [CrossRef]

31. Arndt, D.; Grant, J.R.; Marcu, A.; Sajed, T.; Pon, A.; Liang, Y.; Wishart, D.S. PHASTER: A Better, Faster Version of the PHAST Phage Search Tool. Nucleic Acids Res. 2016, 44, W16-W21. [CrossRef]

32. Wang, Q.; Gong, J.; Huang, X.; Yu, H.; Xue, F. In vitro evaluation of the activity of microencapsulated carvacrol against Escherichia coli with K88 pili. J. Appl. Microbiol. 2009, 107, 1781-1788. [CrossRef]

33. Chang, M.H.; Chen, T.C. Reduction of Campylobacter jejuni in a Simulated Chicken Digestive Tract by Lactobacilli Cultures. J. Food Prot. 2000, 63, 1594-1597. [CrossRef]

34. EFSA Guidance on the assessment of bacterial susceptibility to antimicrobials of human and veterinary importance. EFSA J. 2012, 10. [CrossRef] 
35. Micciche, A.C.; Foley, S.L.; Pavlidis, H.O.; McIntyre, D.R.; Ricke, S.C. A Review of Prebiotics against Salmonella in Poultry: Current and Future Potential for Microbiome Research Applications. Front. Vet. Sci. 2018. [CrossRef]

36. Patterson, C.A. Probiotics Benefits beyond Basic Nutrition; Agriculture and Agri-Food Canada (AAFC): Ottawa, ON, Canada, 2008.

37. Wan, M.L.; Forsythe, S.J.; El-Nezami, H. Probiotics interaction with foodborne pathogens: A potential alternative to antibiotics and future challenges. Crit. Rev. Food Sci. Nutr. 2018, 1-29. [CrossRef]

38. Adhikari, B.; Kwon, Y.M. Characterization of the Culturable Subpopulations of Lactobacillus in the Chicken Intestinal Tract as a Resource for Probiotic Development. Front. Microbiol. 2017, 8, 1389. [CrossRef]

39. Pan, D.; Yu, Z. Intestinal microbiome of poultry and its interaction with host and diet. Gut Microbes 2013. [CrossRef]

40. Lan, P.T.N.; Binh, L.T.; Benno, Y. Impact of two probiotic Lactobacillus strains feeding on fecal lactobacilli and weight gains in chicken. J. Gen. Appl. Microbiol. 2003, 49, 29-36. [CrossRef]

41. Mukai, T.; Arihara, K.; Ikeda, A.; Nomura, K.; Suzuki, F.; Ohori, H. Lactobacillus kitasatonis sp. nov., from chicken intestine. Int. J. Syst. Evol. Microbiol. 2003, 53, 2055-2059. [CrossRef]

42. Kim, S.-Y.; Ogawa, Y.; Adachi, Y. Canine Intestinal Lactic Acid Bacteria Agglutinated with Concanavalin A. J. Vet. Med. Sci. 2006, 68, 1351-1354. [CrossRef]

43. Dec, M.; Urban-Chmiel, R.; Gnat, S.; Puchalski, A.; Wernicki, A. Identification of Lactobacillus strains of goose origin using MALDI-TOF mass spectrometry and 16S-23S rDNA intergenic spacer PCR analysis. Res. Microbiol. 2014, 165, 190-201. [CrossRef]

44. De Angelis, M.; Siragusa, S.; Berloco, M.; Caputo, L.; Settanni, L.; Alfonsi, G.; Amerio, M.; Grandi, A.; Ragni, A.; Gobbetti, M. Selection of potential probiotic lactobacilli from pig feces to be used as additives in pelleted feeding. Res. Microbiol. 2006, 157, 792-801. [CrossRef]

45. Campedelli, I.; Mathur, H.; Salvetti, E.; Clarke, S.; Rea, M.C.; Torriani, S.; Ross, R.P.; Hill, C.; O’Toole, P.W. Genus-Wide Assessment of Antibiotic Resistance in Lactobacillus spp. Appl. Environ. Microbiol. 2018, 85, e01738-18. [CrossRef]

46. Yamazaki, M.; Ohtsu, H.; Yakabe, Y.; Kishima, M.; Abe, H. In vitro screening of lactobacilli isolated from chicken excreta to control Salmonella Enteritidis and Typhimurium. Br. Poult. Sci. 2012, 53, 183-189. [CrossRef]

47. Lin, J.; Sahin, O.; Michel, L.O.; Zhang, Q. Critical Role of Multidrug Efflux Pump CmeABC in Bile Resistance and In Vivo Colonization of Campylobacter jejuni. IAI 2003, 71, 4250-4259. [CrossRef] 